\title{
What is the signal in signal detection?*
}

\author{
PAUL RYDER, RAY PIKE $\dagger$, and LEN DALGLEISH \\ University of Queensland, St. Lucia, Queensland, Australia
}

\begin{abstract}
This study concerns the nature of the stimulus represented along the decision axis in the yes/no auditory detection task. Two contrasting interpretations, absolute and difference representation of the stimulus, are tested by raising the carrier tone embedded within the background "noise" to the level of the signal, on occasional "catch" trials. Results indicate that difference detection may be the preferred mode of operation when a carrier tone is present and the task is a difficult one. Implications for the TSD model are discussed in terms of the relative efficiency of the two detection mechanisms.
\end{abstract}

The purpose of this paper is to compare two interpretations of the sensory decision continuum in the theory of signal detectability (TSD) applied to auditory detection. These interpretations are: (a) the sensory distributions represent amplitude or energy (Version A), and (b) the distributions represent a difference in amplitude or energy (Version B). The importance of this comparison is that it may lead to a specification of precisely what it is that the $\mathrm{O}$ is doing in the auditory signal detection task and answer questions related to the nature of the operational stimulus. The problem has been raised recently by others, for example Macmillan (1971) and Sandusky and Ahumada (1971). In terms of TSD, the problem is concerned with characterizing the precise nature of the decision statistic used by human Os. It does not, and cannot, concern the validity of that theory.

In the yes/no detection situation, with which this paper is concerned, TSD more commonly assumes Interpretation $A$ above. The essential variable in trial-by-trial decision making is assumed to be some function of the intensity of stimulation present during the observation interval, with the $\mathrm{O}$ acting as an amplitude or as an energy (integrative) detector (e.g., Green \& Swets, 1966; Jeffress, 1964). Thus, it is the stimulus intensity (or amount of information, or likelihood ratio, derived from that intensity) during the observation interval that alone determines the decision axis observation point. According to this view of the yes/no task, sensory experience prior to the marked observation interval bears relevance to the decision-making process only insofar as it gives information on the background noise distribution.

The alternative view of the yes/no detection process (Version B) would assume that the $O$ is making difference judgments, via a difference (of amplitude or energy) detector, and that stimulation immediately prior to the observation interval is essential in the determination of the observation point. The difference judgment would be based upon observations taken both

\footnotetext{
* This study was supported by an award from the Australian Research Grants Committee.

+Requests for reprints should be sent to $R$ ay Pike, Department of Psychology, University of Queensland, St. Lucia, Queensland, Australia 4067.
}

before and during the observation interval. Macmillan (1971) has already presented evidence for difference or change detection in a study contrasting detection and recognition. Sandusky and Ahumada (1971), in a study involving the gating on of noise at the commencement of the observation interval, concluded that the response decision might be based on a change in detector level rather than its absolute level. Support for their notion was also provided by Parducci and Sandusky (1970), in a recognition experiment.

To compare these versions, we consider what occurs if on very occasional $\mathrm{N}$ trials the background noise level (per unit bandwidth) is raised to the level at which signals are being presented. According to Version $\mathrm{A}, \mathrm{O}$ should respond as on signal trials, since the information being received now forms part of the $\mathrm{S}+\mathrm{N}$ distribution. According to Version $\mathrm{B}, \mathrm{O}$ should respond as on $\mathrm{N}$ trials, since the information now forms part of the $N$ distribution (i.e., the distribution of differences). Clearly, however, care is required to ensure that these "catch" trials are infrequent, as too many of them could result in a shift in the $\mathrm{N}$ distribution, according to $\mathrm{A}$.

One particularly convenient way of testing the two interpretations, if the above argument is correct, is to use the "pedestal" method in the yes/no paradigm. In this method, a continuous tone is embedded in the noise background and the task is to detect a pulsed increment in that tone. Use of the pedestal ensures a simple way of realizing a "catch" trial, as defined above, by raising the intensity of the pedestal (or "carrier" tone) to that level at which signals are being presented. There is a difficulty here concerning the possibility of transient neural effects which is considered later.

\section{EXPERIMENT I}

\section{Method}

Three experienced monitors, two male and one female, were paid $\$ 1 / \mathrm{h}$ for the experiment.

The task consisted of detecting $1 / 10$-sec pulsed increments of $1 \mathrm{~dB}$ in a continuous $1-\mathrm{kHz}$ carrier tone embedded in a background of white noise (wide band) at an SPL of $63.5 \mathrm{~dB}$. Three different intensities of the carrier tone were used $(66,67$, $68 \mathrm{~dB}$ ), and signals were generated from a Levell transistor decade oscillator (Type TG-66A) and delivered binaurally through TDH39 earphones. 
Table 1

Frequency of "Yes" Responses on "Catch" Trials: Experiment I

\begin{tabular}{|c|c|c|c|c|c|c|c|c|c|c|c|c|}
\hline & \multicolumn{4}{|c|}{ 68-dB Pedestal $(\mathrm{N}=16)$} & \multicolumn{4}{|c|}{ 67-dB Pedestal $(\mathrm{N}=16)$} & \multicolumn{4}{|c|}{ 66-dB Pedestal $(\mathrm{N}=28)$} \\
\hline & $\begin{array}{c}\text { Obser- } \\
\text { ved }\end{array}$ & $\begin{array}{c}\text { Expec- } \\
\text { ted } \\
(S+N)\end{array}$ & $x^{2}$ & $\begin{array}{c}\text { Expec- } \\
\text { ted } \\
(\mathrm{N})\end{array}$ & $\begin{array}{c}\text { Obser- } \\
\text { ved }\end{array}$ & $\begin{array}{c}\text { Expec- } \\
\text { ted } \\
(\mathrm{S}+\mathrm{N})\end{array}$ & $x^{2}$ & $\begin{array}{c}\text { Expec- } \\
\text { ted } \\
(\mathrm{N})\end{array}$ & $\begin{array}{l}\text { Obser- } \\
\text { ved }\end{array}$ & $\begin{array}{c}\text { Expec- } \\
\text { ted } \\
(S+N)\end{array}$ & $x^{2}$ & $\begin{array}{c}\text { Expec- } \\
\text { ted } \\
(\mathrm{N})\end{array}$ \\
\hline S 1 & 0 & 14 & 126.125 & 0.9 & 1 & 14 & 103.806 & 2.3 & 3 & 21 & 71.152 & 5.3 \\
\hline S 2 & 1 & 15 & 218.345 & 1.3 & 1 & 8 & 13.230 & 2.3 & 4 & 14 & 16.284 & 5.7 \\
\hline S 3 & 1 & 14 & 102.703 & .3 & 1 & 12 & 43.517 & 1.3 & 4 & 14 & 16.290 & 4.2 \\
\hline
\end{tabular}

Note $-p<.001$

A simple yes/no situation was employed, and each trial was initiated with the onset of a warning light and carrier tone, which remained on for $5 \mathrm{sec}$. Three seconds after initiation, a signal "marker" light came on for $1 / 10 \mathrm{sec}$, the observation interval. A constant ISI of $10 \mathrm{sec}$ was maintained, and white noise was continuous. The response unit consisted of two keys mounted in front of $S$, and the system was semiautomatically operated.

Os were tested individually in 14 sessions, with three blocks of 50 trials each session and a 5 -min break between blocks. The signal and noise events were equiprobable and randomly presented; Os were informed of this. They were tested in the following manner: four sessions at the highest intensity of the tone, four at the moderate, six at the lowest intensity. The first two sessions at each intensity were taken as practice trials, the others as tests. During test sessions, "catch" trials, where the carrier tone was incremented by $1 \mathrm{~dB}$, were randomly, but infrequently, interspersed among a block of 50. There was a total of 16 such trials at the high and moderate intensity of carrier tone and 28 at the lowest level. At the completion of all sessions, Os were asked whether or not there was any variability in the apparatus, as a check for any awareness on O's part.

\section{Results and Discussion}

Table 1 shows, for each $\mathrm{O}$, the number of expected and observed "yes" responses emitted on "catch" trials, and a chi-square test based on the expected detection performance for $\mathrm{S}+\mathrm{N}$ trials. The test is thus based on the assumption that if $O$ are responding to the absolute level, then observed and expected frequencies will be the same.

Clearly, the Os are responding as may be predicted more by Version B than Version A. Had the expected frequency based on $\mathrm{N}$ trials been large enough, a further test is possible of the "difference detector" hypothesis, that this frequency and the observed are the same, although this would assume a sufficiently powerful test. However, before the results can be unambiguously interpreted, an important question must be discussed.

In the present argument, the crucial decision information arises from the neural equivalent of the intensity of stimulation present at the observation point. It is assumed that if the neural equivalent of signal conditions is created on noise trials, the $S$ should react accordingly. However, the present procedure, using a continuous carrier tone, can be criticized for overlooking the physiological evidence on the discharge characteristics of auditory detection mechanisms.

Studies of transient responses in the discharge activity of auditory neurons (e.g., Parker \& Mundie, 1967;
Kiang, 1965) show that with the onset of stimulation, activity reaches a transient peak above the continuous firing level. Thus, a signal onset is characterized physiologically by an overshoot of the discharging neurons. In the procedure employed, there could have been no characteristic transient on "catch" trials, as the continuous incremented tone begins before the observation point. Any such effect would occur only at the onset of the tone.

In an attempt to overcome this objection, a second experiment was run, using an intermittent carrier tone of $1 / 10 \mathrm{sec}$ pulse duration and $2 / 10 \mathrm{sec}$ "off" duration. Now, with each burst of the carrier, it is assumed that the typical rise and fall characteristics of the discharging neurons will occur and thus the distribution of detection information during the observation interval on "catch" trials is identical to the distribution on normal signal trials. Of course, we cannot be absolutely confident of this assumption. It may be that the effect of repetition at the incremented pulse level makes the sensory effect of the "catch" signal different from a normal signal which is preceded by a nonincremented chain of pulses. However, if this difference does occur, it must be very small. The repetition rates are comparatively low in terms of neuronal action, and it has been shown (e.g., Moller, 1969) that neuronal reaction remains a linear function of stimulation up to very high pulse repetition rates. We would, therefore, claim that the sensory effect of a pulse on "catch" trials is the same as the sensory effect of a signal plus pedestal on normal trials. Consequently, if $\mathrm{O}$ is focussing attention on the observation interval alone, "catch" trials are signal trials; if he is attempting to make difference judgments, "catch" trials are $\mathrm{N}$ trials.

In Experiment II, rather than vary the background pedestal level, we decided to use two levels of signal increment, and thus two levels of "catch" trial increment, 1 and $3 \mathrm{~dB}$. A 3-dB increment within trials is, of course, a fairly easy signal to detect in normal circumstances, and we had expected that Os would notice a $3-\mathrm{dB}$ increment in the intermittent carrier during "catch" trials. Preliminary trials, however, showed that such a $3-\mathrm{dB}$ increment between trials is not noticed when Os are unaware of its possible occurrence, and we therefore went ahead with this condition, questioning Os indirectly on the subject on completion of each session. 
Table 2

Frequency of "Yes" Responses on "Catch" Trials: Experiment II

\begin{tabular}{|c|c|c|c|c|c|c|c|c|c|c|}
\hline & \multicolumn{5}{|c|}{ 1-dB Increment $(\mathrm{N}=48)$} & \multicolumn{5}{|c|}{ 3-dB Increment $(\mathrm{N}=48)$} \\
\hline & $\begin{array}{c}\begin{array}{c}\text { Obser- } \\
\text { ved }\end{array} \\
\end{array}$ & $\begin{array}{c}\text { Expected } \\
(\mathrm{S}+\mathrm{N}) \\
\end{array}$ & $x^{2}$ & $\begin{array}{c}\text { Expected } \\
(\mathrm{N})\end{array}$ & $x^{2}$ & $\begin{array}{c}\begin{array}{c}\text { Obser- } \\
\text { ved }\end{array} \\
\end{array}$ & $\begin{array}{c}\text { Expected } \\
(\mathrm{S}+\mathrm{N})\end{array}$ & $x^{2}$ & $\begin{array}{c}\text { Expected } \\
\text { (N) }\end{array}$ & $x^{2}$ \\
\hline S 1 & 25 & 33 & $\begin{array}{c}6.68 \\
(p<.01)\end{array}$ & 20 & 1.882 & 22 & 34 & $\begin{array}{l}18.60 \\
(\mathrm{p}<.001)\end{array}$ & 15 & $\begin{array}{c}5.875 \\
(\mathrm{p}<.025)\end{array}$ \\
\hline S 2 & 20 & 33 & $\begin{array}{l}19.895 \\
(\mathrm{p}<.001)\end{array}$ & 16 & 1.740 & 19 & 37 & $\begin{array}{l}45.11 \\
(\mathrm{p}<.001)\end{array}$ & 12 & $\begin{array}{c}6.985 \\
(\mathrm{p}<.01)\end{array}$ \\
\hline S 3 & 20 & 40 & $\begin{array}{l}73.681 \\
(\mathrm{p}<.001)\end{array}$ & 10 & $\begin{array}{l}25.750 \\
(\mathrm{p}<.001)\end{array}$ & 16 & 36 & $\begin{array}{l}58.724 \\
(\mathrm{p}<.001)\end{array}$ & 8 & $\begin{array}{c}5.491 \\
(\mathrm{p}<.025)\end{array}$ \\
\hline S 4 & 20 & 31 & $\begin{array}{l}12.864 \\
(\mathrm{p}<.001)\end{array}$ & 17 & .707 & 17 & 39 & $\begin{array}{l}77.19 \\
(\mathrm{p}<.001)\end{array}$ & 8 & $\begin{array}{l}14.564 \\
(\mathrm{p}<.001)\end{array}$ \\
\hline S 5 & 15 & 31 & $\begin{array}{l}19.27 \\
(\mathrm{p}<.001)\end{array}$ & 18 & .988 & 19 & 40 & $\begin{array}{l}48.57 \\
(\mathrm{p}<.001)\end{array}$ & 14 & $\begin{array}{c}3.191 \\
(\mathrm{p}<.1) \\
\end{array}$ \\
\hline
\end{tabular}

\section{EXPERIMENT II}

\section{Method}

Five monitors, three male and two female, were paid $\$ 1 / \mathrm{h}$ for the experiment.

The task consisted of detecting a $1 / 10$-sec pulse incremented by 1 and $3 \mathrm{~dB}$ in an intermittent $1-\mathrm{kHz}$ carrier tone of $0.1 \mathrm{sec}$ duration "on" and .02 sec "off" embedded in a continuous background of white noise ( $63.5 \mathrm{~dB}$ SPL). The intensity of the carrier tone was $66.0 \mathrm{~dB}$.

Os were tested individually in 12 sessions with four blocks of 50 trials each session. There was a 5 -min break between blocks; signal and noise events were equiprobable and randomly presented. Os were given six sessions at the low increment (1-dB signal) and six sessions with the large increment (3-dB signal). The first two sessions at each level were used as practice trials, and throughout test sessions three "catch" trials were randomly interspersed among a block of 50 . There was thus a total of 48 such trials at both increments used.

\section{Results and Discussion}

Table 2 shows the frequency of "yes" responses on critical trials for each increment, chi square for each $S$, and the overall chi-square value obtained by summing the individual results. The individual chi-square results were computed against the expected distribution of responses given each $S$ 's detection performance on $S+N$ trials and also on $\mathrm{N}$ trials.

As a check against the possibility of Os' awareness contaminating results, Os were asked at the completion of each test session whether they thought the apparatus was varying in its output. In the second experiment, no $O$ reported any variability in test sessions; in the first experiment, one $\left.O(O)^{1}\right)$ reported that some trial stimulus levels appeared to fluctuate at the highest intensity of carrier used. Thus, it would seem that, even with easily discriminable signals, Os were generally unaware of the experimental manipulations.

The significant $(\mathrm{S}+\mathrm{N})$ chi squares for all Os indicate that the responses to "catch" trials do not form part of the $\mathrm{S}+\mathrm{N}$ response distribution. As a test of the alternative to this statement, that "catch" trial responses form part of the $\mathrm{N}$ response chi-square values based on the observed performance on $\mathrm{N}$ trials are also given. If the chi-square tests based upon the $\mathbf{N}$ distribution as a comparison had proved nonsignificant (given that the test is sufficiently powerful), the interpretation would have been straightforward. However, the significant results in Table 2 for the (N) chi square would suggest that while a difference-detection process is in operation, Os also discriminate absolutely.

Our finding is in agreement with that of Macmillan (1971), where he describes detection as combining a "change" detector and an integrative detector. His model assumes that recognition requires only the integrative detector, whereas detection may require both mechanisms. Kinchla and Smyzer (1971) also distinguish between recognition and detection in terms which involve a contiguous (in time) comparison between the observation interval and its immediate prior background for the case of detection. The Macmillan (1971) conclusion has, however, been questioned by Leshowitz and Wightman (1971), who maintain that his results are due to a methodological artifact. In a later paper, Macmillan (1973) interprets his data in terms of the interaction of transient effects and stimulus duration, an interpretation which cannot be placed on our own results, where stimulus duration is constant. The Sandusky and Ahumada (1971) study corroborate our present argument for difference detection. Their results were interpreted in terms of the decision being based on a comparison of the observation interval with surrounding noise background when the noise is continuous, and a recall comparision with the previous trial when it is not.

It may be noted that the 3-dB results show greater evidence for the operation of absolute judgment than the 1-dB results. This suggests that there may be a tendency for greater use of absolute judgment with increase of signal strength, which is not an unexpected result, since with a sufficiently strong signal the "catch" trials would, presumably, always be detected. The analogous data for Experiment I have only very small observed and expected frequencies, and are, therefore, not tested. The result may indicate that difference detection may be the more efficient strategy for difficult detection tasks, an argument which raises the question 
of the relative efficiency of the two detection mechanisms. This is discussed below. It must be emphasized again that the Ss were not aware of the 3-dB carrier increment on "catch" trials. Results for this condition are, therefore, uncontaminated by such an awareness, and we take our results to be due to nonartifactual differences in the decision mechanism.

Our results may be incorporated within the framework of TSD as follows. In the first place, neural models for difference detection are not difficult to propose. For example, the "double differentiation" model of Huggins and Licklider (1951), adapted for the time continuum rather than the spatial continuum, would easily explain the transformation from intensity change at sensory input to magnitude of change at the decision process input, although a continuous observation process must now be assumed.

As an alternative and more "molar" explanation, it may be supposed that, with training, the $O$ is capable of anticipating the "observation interval" and commences making observations at a short interval prior to it, thus having an observation, or observations, with which to compare the stimulus observed during the "observation interval" and make a judgment concerning the extent of the difference.

If the latter interpretation is adopted, the TSD model may then assume normal distributions with means at $u_{1}$ and $u_{2}$ for $N$ and $S+N$, respectively, and equal variances of $\sigma^{2}$, and we may deduce that the difference detection observations will be distributed normally, with means of zero and $\mathrm{u}_{2}-\mathrm{u}_{1}$ for $\mathrm{N}$ and $\mathrm{S}+\mathrm{N}$ trials, respectively, so that the difference between the means remains the same. The variance of these distributions will now equal $2 \sigma^{2}(1-r)$, where $r$ is the correlation between observations just before and during the observation interval. The criterion is then set along this difference continuum, and the representation in terms of likelihood ratios is as usual. The efficiency of such a difference detection process in comparison with absolute detection will then depend upon the value of the parameter, $r$. If the value of $r$ is greater than 0.5 , then the difference detection process is more efficient, since $\mathrm{d}^{\prime}$ will be larger due to the smaller variance.
We may conclude that the more efficient the sensory sampling process just before and at the onset of the marked observation interval is, the more efficient it is for an $O$ to use a difference detection strategy. Also, human detection may involve both difference and absolute detection, with the former being dominant when the task is difficult and there is not too much noise in the system. Such a dual processing of information would have obvious advantages. Indeed, it is likely to be the case that human Os use several detection statistics, according to the varying conditions of the detection task. This is, of course, an obvious point to those of us versed in communication theory, but not to those who use TSD merely as a decision-making paradigm.

\section{REFERENCES}

Green, D. A., \& Swets, J. A. Signal detection theory and psychophysics. New York: Wiley, 1S66.

Huggins, W. H., \& Licklider, J. C. R. Place mechanisms of auditory frequency analysis. Journal of the Acoustical Society of America, 1951, 23, 290-299.

Jeffress, L. A. Stimulus-oriented approach to detection. Journal of the Acoustical Society of America, 1964, 36, 766-774.

Kiang, N. Y.-S. Discharge patterns of single nerve fibres in the cat's auditory nerve. Research Monograph No.35, M.I.T. Press, Cambridge, Mass., 1965.

Kinchla, R. A., \& Smyzer, F. A diffusion model of perceptual memory. Perception \& Psychophysics, 1967, 2, 219-229.

Leshowitz, B. \& Wightman, F. L. On the importance of considering the signal's frequency spectrum: Some comments on Macmillan's 'Detection and recognition of increments and decrements in auditory intensity' experiment. Perception \& Psychophysics, 1972, 12, 209-210.

Macmillan, N. A. Detection and recognition of increments and decrements in auditory intensity. Perception \& Psychophysics, $1971,10,233-238$.

Macmillan, N. A. Detection and recognition of intensity changes in tone and noise: The detection-recognition disparity. Perception \& Psychophysics, 1973, 13, 63-75.

Moller, A. R. Unit responses in the rat cochlear nucleus to repetitive transient sounds, Acta Physiologica Scandinavia, $1969,75,542-551$.

Parducci, A., \& Sandusky, A. Limits on the applicability of signal detection theories. Perception \& Psychophysics, 1970, 7, 63-64.

Parker, D. E., \& Mundie, J. R. Neural sensitivity changes following stimulation with transient sound bursts. Journal of Auditory Research, 1967, 7, 287-301.

Sandusky, A., \& Ahumada, A. Contrast in detection with gated noise. Journal of the Acoustical Society of America, 1971, 49 , 1790-1794.

(Received for publication June 8,1973 revision received December $26,1973$. ) 